\title{
Impact of HIV/AIDS on Social Relationships in Rural China
}

\author{
Yurong Zhang ${ }^{1}$, Xiulan Zhang ${ }^{1}$, Tamara Hanko Aleong ${ }^{2}$ and Esme Fuller-Thomson ${ }^{*, 2,3}$ \\ ${ }^{I}$ School of Social Development and Public Policy, Beijing Normal University, Beijing, China \\ ${ }^{2}$ Factor-Inwentash Faculty of Social Work, Ontario, Canada \\ ${ }^{3}$ Department of Family \& Community Medicine University of Toronto, Canada
}

\begin{abstract}
Social support promotes greater medical compliance, better immune system functioning and slows the progress of HIV/AIDS. One in every 50 People Living With HIV/AIDS (PLWHA) is Chinese, yet little is known about the impact of HIV/AIDS on social relationships in China. This study compares the characteristics of those who report that HIV/AIDS had a substantial impact versus a modest impact on their social relationships. We obtained data from a survey of 866 PLWHA in rural China, which was conducted in 2006-2007 in the three Chinese provinces with the highest prevalence of HIV/AIDS. Chi-square test and multiple logistic regression were performed. The analysis shows that PLWHA who had full-blown AIDS $(\mathrm{OR}=1.53 ; 95 \% \mathrm{CI}=1.09-2.13)$ and those who were poor $(\mathrm{OR}=2.19 ; 95 \% \mathrm{CI}=1.52-3.16)$ reported greater impact on their social relationships. The results lay a solid foundation for designing effective policy initiatives and intervention programs aimed at alleviating the impact of HIV/AIDS on social relationships and improving the quality of life of PLWHA.
\end{abstract}

Keywords: HIV/AIDS, China, social relationships, developing world, social support.

\section{INTRODUCTION}

In the mid-1990s, the epidemic of HIV/AIDS spread to central China, primarily through unsafe practices of blood collection. In the following years, HIV transmission through blood and plasma donations and transfusion became effectively contained by new regulations for blood and plasma collection stations. By 2007, the main mode of transmission had shifted to heterosexual transmission (37.9\%) [1]. Approximately 740,000 Chinese are now HIV positive indicating that one in every 50 People Living With HIV/AIDS (PLWHA) in the world are Chinese [2, 3].

Research in Western countries has shown that HIV/AIDS is associated with high rates of co-morbid health problems [4], disability [5, 6], and work discrimination [7]. In the United States, the estimated cost of 40,000 newly diagnosed individuals with HIV was $\$ 36.4$ billion, including $\$ 6.7$ billion in direct medical costs and $\$ 29.7$ billion in productivity losses [8]. In China, the economic impact of HIV/AIDS is estimated to be between RMB 22.5 billion ( $\$ 2.8$ billion U.S.) and RMB 40 billion ( $\$ 5$ billion US) [9].

Rural migrants, who relocate to cities for work, are an emerging high-risk group. The link between population migration and spread of HIV/AIDS has been well established [10]. With an estimated 130 million rural migrant workers [11], China is experiencing the largest internal migration in the history of the world. Migrants often leave their spouses and children behind in their natal village and therefore return regularly for visits. Thus, the potential for the spread of HIV from urban to rural locations is substantial [12-14]. The

*Address correspondence to this author at the Factor-Inwentash Faculty of Social Work, University of Toronto, 246 Bloor St. W., Toronto, ON M5S 1A1, Canada; Tel: 416 978-3269; Fax: 416 978-7072;

E-mail: esme.fuller.thomson@utoronto.ca
Chinese government is now focusing much of its HIV/AIDS prevention interventions towards rural migrants.

Only recently has research on HIV/AIDS in China moved beyond a focus on prevalence and modes of transmission. Social scientists have documented that PLWHA in China suffer serious discrimination and stigmatization from the general public [15], health professionals [16, 17] and government officials [18]. The stigma is partly related to the fact that marginalized groups are at particularly high risk for HIV/AIDS (e.g. injection drug users, men who have sex with men and sex trade workers). Few researchers in China have examined the impact of HIV/AIDS on close personal relationships.

For a greater understanding of how HIV/AIDS affects social relationships and interactions, we must turn to the international literature. In addition to living with a potentially life-threatening and chronic disease, individuals who have an HIV infection face many challenges including the impact of the disease on their personal relationships with intimate partners, friends, family, co-workers and health care professionals [19]. Living with HIV/AIDS results in serious strains with sexual partners [7], often leading to rejection and termination of relationships [20]. AIDS stigma affects the whole family of PLWHA [21]. The social interaction of PLWHA with family members may become particularly difficult and communication problems within the family often arise [20]. HIV/AIDS also increases social isolation, rejection, and avoidance by friends [20, 21], segregation by co-workers $[20,22]$ and deterioration of productive relations with health professionals $[22,23]$.

The impact of HIV/AIDS on social relationships [23] and social support can have serious repercussions for the health of the PLWHA. The importance of social support in coping with HIV/AIDS has been widely documented. In general, 
strong social support has been associated with slower progression of AIDS [24], higher immune system functioning [24-26], and better medical treatment adherence [27-29]. PLWHA who have strong social support networks are more likely to have active coping strategies [30, 31], and better psychological well-being and mental health than those with less robust social support networks [32-36]. The negative impact of HIV/AIDS stigma appears to be buffered among those with strong social support networks [37]. Social support also plays a major role in improving the quality of life of HIV-positive individuals [34, 38-41]. This study reports on 866 PLWHA in Rural China's perception of the impact of HIV/AIDS on two categories of social relationships 1) relatives and/or friends and 2) neighbors.

\section{METHODS}

\section{Survey}

This quantitative study was conducted in Henan, Anhui and Yunnan provinces. Surveys were distributed in counties or districts that have the highest prevalence of HIV/AIDS. Study locations were selected based on regional representations (Central China and Southwest China) and HIV prevalence. Henan, Anhui and Yunnan are three of the most affected areas [1]. Former commercial blood and plasma donations are the main mode of transmission in Henan and Anhui province and injection drug use (IDU) is the main transmission mode in Yunnan.

Individuals who received HIV/AIDS economic or social assistance from the Civil Affairs Department were told about this survey. Those who wished to participate contacted the researchers. PLWHAs either requested that a member of the interview team come to their house or to a neutral location such as a hotel. A total of 866 PLWHA were interviewed. Only one PLWHA was interviewed per household.

The institutional review board of Beijing Normal University approved the study protocol. Once informed consent was obtained from the study participants, trained graduate students administrated standardized questionnaires in face-to-face interviews. Participants were given RMB 20 in compensation for their time. This amount is equal to the average daily wage for a farmer in these provinces (\$3 USD). All participants were informed that they could refuse to participate in the survey at any time and still receive their financial compensation. This cross-sectional study was conducted between November 2006 and February 2007.

\section{Measurement}

This study uses one two-part question to investigate the PLWHA's perception of the "impact of HIV/AIDS on social relationships with 1) relatives and/or friends and on neighbors (other than spouse and children) and 2) neighbors." PLWHA reported the degree to which they perceived that their social relationships were impacted by HIV/AIDS. Their original 5 point likert scale response categories were dichotomized into "limited impact" (including none or a little impact) versus "substantial impact" (including medium, a lot or huge impact).

The following demographic variables were investigated: gender, education level (illiterate, primary school, above primary school), marital status (married, unmarried including widowed, single, or divorced), age (measured by decade: 20 $29,30-39,40-49,50-59$, and 60 and over), household income and living conditions.

We used receipt of Highly Active Anti-Retroviral Therapy (HAART) as a proxy for disease severity. Individuals who received HAART were classified as having AIDS. HAART is provided by the Chinese government free of charge to all individuals with AIDS. Those who did not receive HAART were classified as having HIV only. Time since diagnosis was classified into three categories: 2 or fewer years, 3-6 years, 7 or more years.

\section{Statistic Analysis Strategy}

This study identified the socio-demographic characteristics of those who reported their HIV/AIDS had a substantial impact on their social relationships versus PLWHA who reported limited impact. Chi-square tests and multiple logistic regression analyses were performed with use of SPSS 11.5 software. Chi-square tests were conducted to examine the characteristics of PLWHA who reported that HIV/AIDS had limited impact on their social relationships with relatives and/or friends $(n=424)$ in comparison to those who reported substantial impact on these relationships $(n=439)$. A similar set of analyses contrasted those who reported the HIV/AIDS had limited impact on their social relationships with neighbors $(\mathrm{n}=541)$ versus those who reported substantial impact $(\mathrm{n}=322)$. Multiple logistic regression analyses were conducted separately to estimate $p$ value, odds ratios and their $95 \%$ confidence intervals (C.I) for PLWHA's perceived impact of HIV/AIDS on relatives/ friends and on neighbors.

\section{RESULTS}

A total of 866 PLWHAs were interviewed in this study. The majority of participants were female, married, had completed primary school and were 30-49 years of age (see Table 1). Most of participants were diagnosed with HIV three to six years ago (76\%) and one-quarter of the respondents had full-blown AIDS.

Half of respondents $(50.9 \%)$ perceived that HIV/AIDS had a substantial impact on their social relationships with relatives and/or friends and over one third (37.3\%) perceived a substantial impact on social relationships with neighbors (see Table 1). PLWHA who reported HIV/AIDS had a substantial impact on their social relationships with relatives and/or friends and with neighbors were more likely to be aged 50-59, and were poorer than those who perceived that HIV/AIDS had limited impact on their social relationships. The perceived impact of HIV/AIDS on relationships with relatives and/or friends and with neighbors was greater among those who reported that their living conditions were much lower than that of others in their village. Individuals who reported a deterioration in their relationships with neighbors were less likely to report that neighbors currently provided regular assistance. Individuals who were diagnosed with AIDS as opposed to HIV were more likely to report a substantial impact on both relatives and/or friends and neighbors. 
Table 1. The Impact of HIV/AIDS on Social Relationships by the Characteristics of Persons Living with HIV/AIDS in Rural China

\begin{tabular}{|c|c|c|c|c|c|c|c|}
\hline & $\mathbf{N}(\%)$ & \multicolumn{3}{|c|}{ With Relatives and/or Friends } & \multicolumn{3}{|c|}{ With Neighbors } \\
\hline Male & $415(47.9 \%)$ & $49.8 \%$ & $45.8 \%$ & & $47.5 \%$ & $48.1 \%$ & \\
\hline Female & $451(52.1 \%)$ & $50.2 \%$ & $54.2 \%$ & & $52.5 \%$ & $51.9 \%$ & \\
\hline Illiterate & $286(33.1 \%)$ & $30.7 \%$ & $35.6 \%$ & & $33.3 \%$ & $33.0 \%$ & \\
\hline Primary school & $411(47.5 \%)$ & $49.3 \%$ & $45.7 \%$ & & $46.8 \%$ & $48.6 \%$ & \\
\hline Above primary school & $168(19.4 \%)$ & $20.0 \%$ & $18.7 \%$ & & $20.0 \%$ & $18.4 \%$ & \\
\hline Marital status & & & & 0.36 & & & 0.85 \\
\hline $20-29$ & $67(7.7 \%)$ & $9.4 \%$ & $5.7 \%$ & & $7.6 \%$ & $7.5 \%$ & \\
\hline $30-39$ & $291(33.6 \%)$ & $34.7 \%$ & $32.6 \%$ & & $33.8 \%$ & $33.2 \%$ & \\
\hline $40-49$ & $323(37.3 \%)$ & $37.5 \%$ & $37.4 \%$ & & $38.6 \%$ & $35.4 \%$ & \\
\hline $50-59$ & $147(17.0 \%)$ & $13.2 \%$ & $20.7 \%$ & & $14.4 \%$ & $21.4 \%$ & \\
\hline$\geq 60$ & $38(4.4 \%)$ & $5.2 \%$ & $3.6 \%$ & & $5.5 \%$ & $2.5 \%$ & \\
\hline Time since diagnosis, year & & & & 0.32 & & & 0.69 \\
\hline$\leq 2$ & $27(3.1 \%)$ & $4.0 \%$ & $2.3 \%$ & & $3.5 \%$ & $2.5 \%$ & \\
\hline $3-6$ & $653(76.0 \%)$ & $75.8 \%$ & $76.2 \%$ & & $75.8 \%$ & $76.3 \%$ & \\
\hline Low & $288(33.3 \%)$ & $25.9 \%$ & $40.3 \%$ & & $31.4 \%$ & $36.3 \%$ & \\
\hline Middle & $289(33.4 \%)$ & $31.8 \%$ & $35.1 \%$ & & $32.2 \%$ & $35.7 \%$ & \\
\hline High & $289(33.4 \%)$ & $42.2 \%$ & $24.6 \%$ & & $36.4 \%$ & $28.0 \%$ & \\
\hline $\begin{array}{l}\text { Living conditions comparing } \\
\text { to other families in the village }\end{array}$ & & & & 0.00 & & & 0.00 \\
\hline Similar to others & $170(20.1 \%)$ & $26.8 \%$ & $13.5 \%$ & & $23.4 \%$ & $14.5 \%$ & \\
\hline A lit lower than others & $225(26.6 \%)$ & $27.5 \%$ & $25.7 \%$ & & $27.6 \%$ & $24.7 \%$ & \\
\hline Much lower than others & $451(53.3 \%)$ & $45.7 \%$ & $60.8 \%$ & & $49.0 \%$ & $60.9 \%$ & \\
\hline Status of relationship with neighbors & & & NA & & & & 0.00 \\
\hline Neighbors do not provide any assistance & $95(11.3 \%)$ & & & & $7.5 \%$ & $18.2 \%$ & \\
\hline $\begin{array}{l}\text { Neighbors may provide } \\
\text { some assistance if there is a crisis }\end{array}$ & $162(19.3 \%)$ & & & & $14.0 \%$ & $28.7 \%$ & \\
\hline Some neighbors provide regular assistance & $262(31.2 \%)$ & & & & $31.2 \%$ & $31.4 \%$ & \\
\hline Most neighbors provide regular assistance & $321(38.2 \%)$ & & & & $47.4 \%$ & $21.8 \%$ & \\
\hline
\end{tabular}

As shown in the logistic regression analyses (See Table 2), PLWHA had twice the odds of reporting that HIV/AIDS had an impact on their relationships with relatives and/or friends if they were aged 50-59 in comparison to those aged 20 to 29. Those in the lowest income bracket had twice the odds of those in the highest income category of reporting that 
Table 2. Multiple Logistic Regression Analysis of Reporting the Impact of HIV/AIDS on Social Relationships Among PLWHA $(\mathbf{n}=\mathbf{8 6 6})$

\begin{tabular}{|c|c|c|c|c|c|c|}
\hline \multirow[b]{2}{*}{ Variables } & \multicolumn{3}{|c|}{ with Relatives and/or Friends } & \multicolumn{3}{|c|}{ with Neighbors } \\
\hline & Odds Ratio & $95 \%$ CI & $p$ & Odds Ratio & $95 \% \mathrm{CI}$ & $p$ \\
\hline \multicolumn{7}{|l|}{ Gender } \\
\hline Male & 1.00 & Reference & & 1.00 & Reference & \\
\hline Female & 0.90 & $0.66-1.24$ & 0.52 & 0.82 & $0.59-1.14$ & 0.23 \\
\hline \multicolumn{7}{|l|}{ Education Level } \\
\hline Illiterate & 1.00 & Reference & & 1.00 & Reference & \\
\hline Primary school & 0.89 & $0.63-1.26$ & 0.51 & 1.07 & $0.75-1.53$ & 0.72 \\
\hline Above Primary school & 0.93 & $0.60-1.45$ & 0.75 & 0.96 & $0.61-1.50$ & 0.84 \\
\hline \multicolumn{7}{|l|}{ Marital status } \\
\hline Unmarried & 1.00 & Reference & & 1.00 & Reference & \\
\hline Married & 1.27 & $0.91-1.78$ & 0.16 & 1.15 & $0.82-1.63$ & 0.42 \\
\hline \multicolumn{7}{|l|}{ Age by decade, yr } \\
\hline $20-29$ & 1.00 & Reference & & 1.00 & Reference & \\
\hline $30-39$ & 1.37 & $0.73-2.59$ & 0.32 & 1.01 & $0.53-1.91$ & 0.98 \\
\hline $40-49$ & 1.50 & $0.79-2.84$ & 0.21 & 1.01 & $0.53-1.92$ & 0.98 \\
\hline $50-59$ & $2.37 *$ & $1.18-4.77$ & 0.01 & 1.75 & $0.87-3.51$ & 0.11 \\
\hline$\geq 60$ & 1.01 & $0.41-2.48$ & 0.98 & 0.49 & $0.18-1.34$ & 0.16 \\
\hline \multicolumn{7}{|l|}{ Income (per capita) } \\
\hline High & 1.00 & Reference & & 1.00 & Reference & \\
\hline Low & $2.19 * * *$ & $1.52-3.16$ & 0.00 & 1.27 & $0.87-1.85$ & 0.20 \\
\hline Middle & $1.69 * *$ & $1.19-2.41$ & 0.004 & 1.30 & $0.90-1.87$ & 0.16 \\
\hline \multicolumn{7}{|c|}{ Living conditions comparing to other families in the village } \\
\hline Similar to others & 1.00 & Reference & & 1.00 & Reference & \\
\hline Much lower than others & $2.18 * * *$ & $1.47-3.24$ & 0.00 & $1.93 * *$ & $1.27-2.93$ & 0.002 \\
\hline A lit lower than others & $1.76^{* *}$ & $1.15-2.70$ & 0.01 & 1.50 & $0.95-2.36$ & 0.08 \\
\hline \multicolumn{7}{|l|}{ Clinical stage } \\
\hline HIV & 1.00 & Reference & & 1.00 & Reference & \\
\hline AIDS & $1.53 *$ & $1.09-2.13$ & 0.013 & $1.62 * *$ & $1.16-2.25$ & 0.005 \\
\hline
\end{tabular}

“*p $\leq 0.05, * * \mathrm{p} \leq 0.01, * * * \mathrm{p} \leq 0.001$.

HIV/AIDS had a substantial impact on their relationship with relatives and/or friends. In comparison to those who reported their living standard was average in their village, those who reported a much lower standard of living had twice the odds of reporting that HIV/AIDS substantially affected their relationship with relatives and/or friends. Respondents with AIDS had 53\% higher odds of reporting that HIV/AIDS had a substantial impact on relationship with relatives and/or friends than respondents who were HIV positive but did not have AIDS.

Similarly, the odds of reporting that HIV/AIDS had a substantial impact on relationships with neighbors were higher among those with AIDS as opposed to HIV, and those who reported their living conditions were much lower than other villagers. In contrast to the bivariate findings, age and income level were not statistically significant factors in the multiple logistic regression analysis focused on relationship with neighbors.

\section{DISCUSSION}

Half of the respondents reported that they perceived that HIV/AIDS had a substantial impact on social relationships with relatives and/or friends. One third of the PLWHA in this study reported the disease had a substantial impact on their social relationships with neighbors. The poorest respondents and those with AIDS as opposed to HIV were the most likely to report social relationships were seriously affected by their illness.

The long-term consequences of such widespread perceived impact of HIV/AIDS on social relationships may be considerable. Previous research has demonstrated the importance of strong social support networks for PLWHA 
[30-36,42]. As was discussed above, social support promotes greater medical compliance, improves immune system functioning and slows the progress of HIV/AIDS [24-29,43]. Neighbors are an integral part of many rural Chinese's social support network. Among those who reported limited impact of HIV/AIDS on relations with neighbors, almost one-half reported that neighbors regularly provided assistance to them. For those who claimed that HIV/AIDS had substantial impact on relationships with neighbors, only one in five relied on neighbors for regular assistance.

Our findings indicate that those with lower socioeconomic status were more likely to report that HIV/AIDS has had a substantial impact on their social relationships. The respondents' subjective perspective of their living standard relative to other villagers was strongly associated with the perceived impact of HIV/AIDS on social relationships with relatives and/or friends and with neighbors. Income level was associated with the perceived impact of HIV/AIDS on social relationships with relatives and/or friends but not with neighbors. Poorer individuals may need to rely more intensely on extended family members, friends and/or neighbors to help with caregiving and/or financial assistance. In contrast, affluent AIDS households can often manage with no or minimal economic assistance or tangible support from relatives. It is possible that the additional demands on family and friends required by impoverished PLWHA may put undue strain on their relationships. If this is so, one potential strategy to mitigate the negative impact of HIV/AIDS on social relationships is to take measures to strengthen the economic status of AIDS households. Although the government provides financial assistance to PLWHA, the amount received is only approximately $10 \%$ of the average annual household income. Governments or Non-Governmental Organizations could develop programs or create supportive policies including micro-loan services, tax benefits, and support groups to assist PLWHA in finding employment suitable to their health status. Such a strategy could not only increase household income, but could decrease the negative impact of HIV/AIDS and improve quality of life.

PLWHAs were more likely to report that HIV/AIDS had a substantial impact on relationships both with relatives and/or friends and with neighbors if the disease had progressed to the AIDS stage. The caregiving demands on an individual's social support network and the concomitant potential for strain in these relationships often increase as the illness progresses. Another hypothesis results from the fact that the disease is harder to conceal once it becomes symptomatic. North American literature suggests that those with AIDS symptomatology face greater AIDS stigma [44]. It may be this higher level of stigma that results in declining quality of some social relationships.

Individuals aged 50-59 were more than twice as likely to report an impact on their relationships with relatives and/or friends in comparison to PLWHA in their 20s. If the PLWHA's perceived impact of HIV/AIDS on social relationships is primarily mediated through stigma, this study's finding is not congruent with previous research. A meta-analysis based on 24 peer reviewed journal articles published since 2000 in North America shows that the stigma level was significantly higher in younger age groups
[44]. Liu's [15] study in rural China found that age did not play a role in the level of AIDS stigma. Differences in sampling strategy and ways of measuring stigma may have contributed to these conflicting findings. One possible explanation for our result is that PLWHA in this age group are often the main household breadwinner. It is possible through their employment outside the home that they are exposed to greater discrimination. In addition, as PLWHA become too ill to work as they get older, the presence of the disease may become more visible to others. An alternative explanation is due to cohort differences. PLWHA who are currently 50-59 years of age represent many of the first group of people infected with HIV in the mid-1990s (especially in central China). At that time, there was no public education on AIDS in China. Therefore, those who were infected during the middle 1990s were exposed to high levels of AIDS stigma and discrimination. Recently, however, there has been a decline in social stigma faced by PLWHA. Over the past decade, Chinese federal and provincial governments conducted public education campaigns to increase knowledge about HIV/AIDS and to decrease stigma [1]. Many respondents in our study in Henan and Anhui provinces mentioned that this government initiated campaign was extremely helpful in improving the social acceptance of PLWHA. In addition, the programs to provide financial assistance to PLWHA and free HAART indicate government's support for PLWHA. These programs have eased the economic impact of the disease and made ill PLWHA less dependent on family, friends and neighbors. Other studies of rural Chinese PLWHA are needed to determine if the same age pattern in perceived impact of social relationships can be replicated and to investigate other possible mechanisms which might explain this perplexing finding.

Free provision of HAART and other drugs is an important policy for which the Chinese government should be commended. However, our finding that those with fullblown AIDS symptoms were more likely to report that illness negatively affected their social relationships underlines the need for better medication to slow the progress of the disease.

Although there are policies in China addressing the needs of those with HIV/AIDS, further outreach and public education is needed. Intervention research must investigate the impact of financial subsidies, rural home-health care programs, support groups and public education on the social relationships of Chinese PLWHA. Representative rural and urban samples of Chinese PLWHA will improve the generalizability of future studies. Such studies are necessary because of substantial economic disparities and cultural differences between urban and rural Chinese regions.

There are several limitations to this study. The sensitivity of AIDS as a topic of investigation and the challenge of locating a large sample of PLWHA to complete the study resulted in our use of non- random sampling. Due to our sampling strategy, the vast majority of respondents (over $70 \%$ ), received government financial assistance for PLWHA. Furthermore, our sample was predominantly drawn from villages with a high prevalence of HIV/AIDS where the transmission mode was primarily through blood and plasma donations. It is possible that the social issues faced by 
PLWHA are more severe in villages with few PLWHA or with other modes of transmission. Thus, we cannot be confident that our findings are representative of the experience of rural Chinese PLWHA. Another major limitation is that the impact of HIV/AIDS on social relationships was measured by self-report. Although the subjective perception of the PLWHA of the impact of HIV/AIDS on their social relationships has some advantages, objective measurement of social support in longitudinal studies would provide a better measure of the impact of HIV/AIDS on the provision and availability of social support. We also do not have information about the transmission mode of the disease. Research indicated this is an important factor in stigma $[45,46]$. Other important factors to consider in future research would be ethnic minority status and history of internal migration by the PLWHA and their sexual partners.

Despite these limitations, this study provided the largest survey to date of rural Chinese PLWHA perception of the social impact of HIV/AIDS on their social relationships with friends, extended families and neighbors. The findings suggest the need for government policy and program attention to the issue of poverty and social marginalization among PLWHA.

\section{ACKNOWLEDGEMENTS}

The study was funded by the Health Policy and Systems Research, an initiative of the Global Forum for Health Research in Collaboration with the World Health Organization. This publication is an output of the POVILL Project, supported by the Sixth Framework Programme of the European Commission.

We would like to thank Marion Hurd for her assistance in preparing this manuscript.

\section{REFERENCES}

[1] State Council AIDS Working Committee Office, UN Theme Group on AIDS in China. A Joint Assessment of HIV/AIDS Prevention, Treatment and Care in China (2007). Available from: http://www. un.org.cn/cms $/ \mathrm{p} /$ resources $/ 30 / 491 /$ content.html [Accessed: 20 October 2008].

[2] Ministry of Health (MOH, China), UNAIDS, WHO. A Joint Assessment of HIV/AIDS Epidemic in China (31 May 2010). Available from: http://www.moh.gov.cn/publicfiles///business/cms resources/mohjbyfkzj/cmsrsdocument/doc9721.pdf [Accessed: 20 March 2011].

[3] Fast facts on HIV. WHO/UNAIDS (2010). Available from: http://w ww.who.int/hiv/data/fast_facts/en/index.html [Accessed: 20 March 2011].

[4] Guss DA. The acquired immune deficiency syndrome: An overview for the emergency physician. J Emerg Med 1994; 3: 375-84.

[5] Stoff DM, Mitnick L, Kalichman S. Research issues in the multiple diagnoses of HIV/AIDS, mental illness and substance abuse. AIDS Care 2004; 16(Suppl 1): 1-5.

[6] Stoff DM. Mental health research in HIV/AIDS and aging: Problems and prospects. AIDS 2004; 18(Suppl 1): 3-10.

[7] Alonzo AA, Reynolds NR. Stigma, HIV and AIDS: an exploration and elaboration of a stigma trajectory. Soc Sci Med 1995; 3: 30315.

[8] Hutchinson AB, Farnham PG, Dean HD, et al. The Economic Burden of HIV in the United States in the Era of Highly Active Antiretroviral Therapy: Evidence of Continuing Racial and Ethnic Differences. J Acquir Immune Defic Syndr 2006; 4: 451-7.

[9] The Socioeconomic Impact of HIV/AIDS Research Team. Socialeconomic Impact of HIV/AIDS in China. (August 2002). Available from: http://www.unicef.org/evaldatabase/files/CHN_2001_006.pdf [Accessed: 21October 2008].
[10] Parrado EA, Flippen CA, McQuiston C. Use of commercial sex workers among Hispanic migrants in North Carolina: implications for the spread of HIV. Perspect Sex Reprod Health 2004; 4: 150-6.

[11] National Bureau of Statistics of China. 30th anniversary of China's reform and opening up Series Report No. 8: Agriculture and Rural Economy. (5 November 2008). Available from: http://www.stats. gov.cn/tjfx/ztfx/jnggkf30n/t20081105 402514634.htm [Accessed: 18 November 2008].

[12] Li X, Zhang L, Stanton B, et al. HIV/AIDS-related sexual risk behaviors among rural residents in China: Potential role of rural-tourban migration. AIDS Educ Prev 2007; 5: 396-407.

[13] Quinn TC. Population migration and the spread of types 1 and 2 human immunodeficiency viruses. Proc Natl Acad Sci USA 1994 7: $2407-14$

[14] Yang X. Temporary Migration and the spread of STDs/HIV in China: is there a link? Int Migration Rev 2004; 1: 212-35.

[15] Liu N. HIV/AIDS, stigma, and social discrimination: A quantitative analysis of AIDS patients and ordinary villagers in two Chinese rural communities. Sociol Stud 2005; 20: 136-64 (in Chinese).

[16] Wang Y, Zhang KN, Zhang KL. HIV/AIDS related discrimination in health care service: a cross-sectional study in Gejiu city, Yunnan province. Biomed Environ Sci 2008; 2: 124-8.

[17] Yang Y, Zhang KL, Chan KY, et al. Institutional and structural forms of HIV-related discrimination in health care: A study set in Beijing. AIDS Care 2005; 17(Suppl 2): 129-40.

[18] Jin W. Analysis of the finding of a survey regarding discrimination against HIV/AIDS among government and party officials. Chin J AIDS STD 2005; 2: 88-90 (in Chinese).

[19] Greene K, Frey LR, Derlega VJ. Interpersonalizing AIDS: Attending to the Personal and Social Relationships of Individuals Living with HIV and/or AIDS. J Soc Pers Relat 2002; 1: 5-17.

[20] Varas-Diaz N, Serrano-Garcia I, Toro-Alfonso J. AIDS-related stigma and social interaction: Puerto Ricans living with HIV/AIDS. Qual Health Res 2005; 2: 169-87.

[21] Bogart LM, Cowgill BO, Kennedy D, et al. HIV-related stigma among people with hiv and their families: a qualitative analysis. AIDS Behav 2008; 2: 244-54.

[22] Chesney MA, Smith AW. Critical delays in HIV testing and care: the potential role of stigma. Am Behav Sci 1999; 7: 1162-74.

[23] Kalichman SC. Understanding AIDS: advances in research and treatment. 2nd ed. Washington, D.C. American Psychological Association (APA) 1998.

[24] Leserman J, Jackson ED, Petitto JM, et al. Progression to AIDS: The effects of stress, depressive symptoms, and social support. Psychosom Med 1999; 3: 397-406.

[25] Cohen M, Arad S, Lorber M, et al. Psychological distress, life stressors, and social support in new immigrants with HIV. Behav Med 2007; 2: 45-54.

[26] Theorell T, Blomkvist V, Jonsson $\mathrm{H}$, et al. Social support and the development of immune function in human immunodeficiency virus infection. Psychosom Med 1995; 1: 32-6.

[27] Catz SL, Kelly JA, Bogart LM, et al. Patterns, correlates, and barriers to medication adherence among persons prescribed new treatments for HIV disease. Health Psychol 2000; 2: 124-33.

[28] Cox LE. Social support, medication compliance and HIV/AIDS Soc Work Health Care 2002; 1-2: 425-60.

[29] Power R, Koopman C, Volk J, et al. Social support, substance use, and denial in relationship to antiretroviral treatment adherence among HIV-infected persons. AIDS Patient Care STDs 2003; 5: 245-52.

[30] Crystal S, Akincigil A, Sambamoorthi U, et al. The diverse older HIV-positive population: A national profile of economic circumstances, social support, and quality of life. J AIDS 2003; (Suppl 2): 76-83.

[31] Onwumere J, Holttum S, Hirst F. Determinants of quality of life in Black African women with HIV living in London. Psychol Health Med 2002; 1: 61-74.

[32] Catz SL, Gore-Felton C, McClure JB. Psychological distress among minority and low-income women living with HIV. Behav Med 2002; 2 : 53-60

[33] Cowdery JE, Pesa JA. Assessing quality of life in women living with HIV infection. AIDS Care 2002; 2: 235-45.

[34] Hays RB, Chauncey S, Tobey LA. The social support networks of gay men with AIDS. J Commun Psychol 1990; 4: 374-85. 
[35] Nott KH, Vedhara K, Power MJ. The role of social support in HIV Infection. Psychol Med 1995; 5: 971-84.

[36] Pergami A, Gala C, Burgess A, et al. Heterosexuals and HIV disease: A controlled investigation into the psychosocial factors associated with psychiatric morbidity. J Psychosom Res 1994; 4: 305-13.

[37] Galvan FH, Davis EM, Banks D, et al. HIV Stigma and Social Support among African Americans. AIDS Pat Care STDs 2008; 5: 423-36.

[38] Burgoyne R, Renwick R. Social support and quality of life over time among adults living with HIV in the HAART era. Soc Sci Med 2004; 7: 1353-66.

[39] Friedland J, Renwick R, McColl M. Coping and social support as determinants of quality of life in HIV/AIDS. AIDS Care 1996; 1: 15-31.

[40] Gielen AC, McDonnell KA, Wu AW, et al. Quality of life among women living with HIV: The importance violence, social support, and self care behaviors. Soc Sci Med 2001; 2: 315-22.

[41] Kelly JA, Murphy DA, Bahr GR, et al. Outcome of CognitiveBehavioral and Support Group Brief Therapies for Depressed, HIV-Infected Persons. Am J Psychiatry 1993; 11: 1679-86.
[42] Hays RB, Turner H, Coates TJ. Social support, AIDS-related symptoms, and depression among gay men. J Consult Clin Psychol 1992; 3: 463-9.

[43] Cox BJ, Enns MW, Clara IP. Psychological dimensions associated with suicidal ideation and attempts in the national comorbidity survey. Suicide Life-Threat Behav 2004; 3: 209-19.

[44] Gadalla T, Logie C. Health and demographic correlates of stigma toward people living with HIV/AIDS: a meta-analysis. (13 November 2008). Available from: http://www.ohtnweb.ca/webgtre ports/frmswitch.aspx?intSessionId=1080\&intCompId=14 [Accessed: 20 November 2008]

[45] Gao J, Zheng W, Shi Xiao-Ming, et al. Survey on HIV/AIDSrelated stigma and discrimination among residents in rural community with a past history of paid blood donation. Chin J AIDS STDs 2004; 10: 175-7 (In Chinese).

[46] Borchert J, Rickabaugh CA. When illness is perceived as controllable: the effects of gender and mode of transition on AIDSrelated stigma. Sex Roles 1995; 33: 657-68 